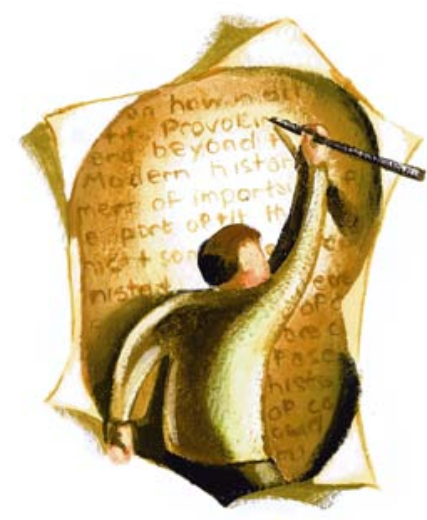

\section{Selling sickness}

In her review of Selling Sickness: How the World's Biggest Pharmaceutical Companies are Turning Us All into Patients, Miriam Shuchman ${ }^{1}$ ignores one of the central premises of the book. The authors, Ray Moynihan and Alan Cassels, argue that physicians have been conscripted into a systematic campaign by the pharmaceutical industry to broaden the boundaries of illness so that drugs can be prescribed to formerly healthy people. As they note, "a health system that allows drug companies to play a role in defining who is sick is fundamentally unhealthy."

\section{Ian Hammond}

Department of Diagnostic Imaging

Ottawa Hospital

University of Ottawa

Ottawa, Ont.

\section{REFERENCE}

I. Brand-name disease [book review]. CMAJ 2006;174:819-20.

DOI:I0.1503/cmaj.1060075

\section{Another proposal for}

\section{primary care}

I find the rhetoric around private clinics, enrolment fees and annual dues for "gold-plated" medical services pretty amusing. As described in a recent article by Wayne Kondro, ${ }^{1}$ clients at the Copeman clinics would get 24 -hour access to physicians and as-needed house calls. But wait - isn't that what we family docs are supposed to be providing? It certainly started out that way.

Here's my proposal. I am willing to compete with the Copeman clinics, on the following terms. For the sum of $\$ 250$ per year per patient, without an enrolment fee, I will provide the same core services and do health promotion and teaching; I will also set my patients up with specialists as required. I won't need to bill the provincial system, because with about 2000 patients, I will cover my overhead and have a reasonable income, without any intermediaries like Copeman (although I would probably need to employ a nurse practitioner).

With this arrangement, I'm sure other like-minded family docs would be willing to sign up, and the problem of access to primary care would be taken care of. Does this make any sense to the Canadian ministers of health?

\section{Tom W. Bell}

Family Physician

Peterborough, Ont.

\section{REFERENCE}

I. Kondro W. Copeman clinics come under scrutiny. CMAJ 2006;174(6):753.

DOI:Io.I503/cmaj.1060076

\section{Inconsistent position}

\section{on SSRI ads}

Dr. Wayne Goodman, Chair of the Psychopharmacologic Drugs Advisory Committee of the US Food and Drug Administration (FDA), is quoted at the beginning of Colin Meek's article ${ }^{1}$ as saying that he thinks ads about SSRIs stating that the drugs correct a serotonin "imbalance" are not based on scientific evidence and should be prohibited. At the end of the article, however, Dr. Goodman refuses to comment on whether the FDA should ban the ads and he endorses the admittedly unsupported claim that the drugs normalize some kind of chemical imbalance. These positions are clearly inconsistent, especially given that only the FDA has the explicit power and mandate to regulate drug ads in the United States.

For the general public, ads are crucial determinants of the perceived effects of drugs. Dr. Goodman's comments illustrate that, despite a vast drug regulatory bureaucracy, profit-focused manufacturers can make whatever claims they like about their products, with no attention to scientific evidence and no real fear of consequences. A similar situation existed about Ioo years ago, during the era of "patent medicines." This is just one more sign that the adman is rapidly replacing the physician as the true intermediary between patients and their drugs.

\section{David Cohen}

School of Social Work Florida International University Miami, Fla.

\section{REFERENCE}

I. Meek C. SSRI ads questioned. CMAJ 2006;174(6): 754 .

Competing interests: None declared.

DOI:I0.1503/cmaj.1060070

\section{Diabetes susceptibility}

The hypothesis advanced by Hertzel Gerstein and Laura Waltman, ${ }^{1}$ explaining why the age-adjusted prevalence of diabetes ranges from about $5 \%$ among people of European ancestry to $40 \%$ or higher in newly westernized Aboriginal populations, represents virtually the same hypothesis that I first proposed in $1998,{ }^{2}$ corroborated in $1999^{3}$ and further developed in 2004. ${ }^{4}$

The substantial difference between their hypothesis and mine is that they regard Europeans' adaptation to a diabetogenic environment as a relatively recent phenomenon, beginning 300 to 400 years ago, whereas I believe that it occurred several millennia earlier, when incipient agriculture, apiculture, sheep farming, and rudimentary technologies enabled Europeans' ancestors to produce "genetically unknown 